\title{
Adesão a Terceirização das Operações Logísticas: A Perspectiva de um Coordenador de Operações
}

\section{Membership to outsourcing Operations Logistics: TheProspect an Operations Coordinator}

\author{
Daniela Aparecida de Alcântara Quintaneiro \\ Mestranda em Administração - Faculdade Novos Horizontes \\ Rua Alvarenga Peixoto, 1270, Bairro Santo Agostinho, Belo Horizonte, MG, Brasil \\ CEP: 30.180-121, fone: (31) 9658-0965, e-mail: daniela.quintaneiro@mestrado.unihorizontes.br
}

\author{
Caissa Veloso e Sousa \\ Doutora em Administração de Empresas (UFMG). Professora e Pesquisadora Faculdade Novos Horizontes \\ Mestrado Acadêmico em Administração \\ Rua Alvarenga Peixoto, 1270 - Bairro Santo Agostinho, Belo Horizonte, MG, Brasil, CEP: 30.180-121, fone: (31) \\ 9337-4933, e-mail: caissaveloso@yahoo.com.br
}

\section{RESUMO}

Tendo em vista as mudanças na sociedade moderna, decorrentes especialmente das novas tecnologias de informação e comunicação (TIC's), e a intensificação do processo de globalização, as organizações têm buscado atualizar suas tecnologias, processos e ferramentas de trabalho, garantindo competitividade e posição favorável no mercado atuante. Neste contexto, uma das estratégias utilizadas é a terceirização das atividades que não são inerentes ao objetivo final da organização, dentre as quais se caracterizam os serviços logísticos. No Brasil, anualmente, são gastos cerca de R 192 bilhões, ou 11,7\% do Produto Interno Bruto Nacional, com logística. Deste montante, aproximadamente $63 \%$ são direcionados para pagamento de terceiros, ou seja, para os prestadores de serviços logísticos. Considerando-se esta representatividade do setor para a economia nacional, o presente trabalho teve como objetivo demonstrar os motivos que conduzem as empresas a optarem pela terceirização dos serviços de distribuição logística, segundo a visão de um coordenador de operações logísticas. Para tanto, foi realizada uma pesquisa qualitativa básica a partir de entrevista, com a utilização de um roteiro semiestruturado junto ao coordenador de operações logística da AGV Logística, responsável pelas operações da empresa aqui denominada Betha. Segundo o entrevistado, a empresa Betha opta em terceirizar seus serviços logísticos visando redução nos custos de contratação e manutenção predial, desenvolvimento e manutenção de mão de obra qualificada, investimento em tecnologia de informação e em equipamentos de movimentação. Além dos custos, outras razões para a terceirização são o maior foco no negócio e a flexibilidade operacional.

Palavras chave: Terceirização; Serviços Logísticos; Distribuição Logística.

\section{ABSTRACT}

Given the changes in modern society, especially under the new technologies of information and communication technologies (ICT's), and the intensification of globalization, organizations have sought to upgrade their technologies, processes and tools, ensuring competitiveness and favorable active in the market. In this context, one of the strategies used is the outsourcing of activities that are not inherent to the ultimate goal of the organization, among which are characterized logistics services. In

\footnotetext{
${ }^{1}$ Revisado pelos pares em 14.06.2013 (blind review). Ajustado e aceito para publicação em 26.08.2013. Recomendado para publicação por José Ribamar Marques de Carvalho (Editor Científico). Publicado em 15.09.2013. Instituição responsável UACC/CCJS/UFCG
} 
Brazil annually are spent approximately R \$ 192 billion, or 11.7\% of the National Gross Domestic Product, with logistics. Of this amount, approximately $63 \%$ are directed to third-party payment, or for logistics service providers. Given this representation of the sector to the national economy, the present study aimed to demonstrate the reasons that lead companies to opt for outsourcing of logistics distribution, in the view of a coordinator logistics operations. A survey was conducted from basic qualitative interviews, using a semi-structured screenplay, with the coordinator of logistics operations at AGV Logistics, responsible for the operations of the company here called Betha. According to the respondent, Betha the company chooses to outsource their logistics services in order to reduce the costs of hiring and building maintenance, development and maintenance of skilled labor, investment in information technology and handling equipment. Besides cost, other reasons for outsourcing are the main focus in business and operational flexibility.

Keywords: Outsourcing, Logistics Services, Logistics Distribution.

\section{INTRODUÇÃO}

Tendo em vista as mudanças na sociedade moderna, decorrentes especialmente das novas tecnologias de informação e comunicação (TIC's), e a intensificação do processo de globalização, as empresas buscam atualizar suas tecnologias, processos e ferramentas de trabalho para conseguirem atender as exigências de seus clientes, garantirem maior competitividade e posição favorável no mercado atuante.

Nesse contexto, visando atender as necessidades de seus clientes e a construção de relacionamentos duradouros com estes, as organizações têm procurado desenvolver novos produtos, serviços e processos de produção, que sejam capazes de aprimorar essas relações. É neste cenário que as empresas prestadoras de serviços têm procurado inserir novas ferramentas, tecnologias e métodos para a prestação de serviços de qualidade, em tempo hábil. Para tanto, sabe-se que é importante ter um aparato de auxílios para exercer esta atividade com a qualidade que o cliente espera, ou seja, criar valor para o cliente (BALLOU, 2006).

A terceirização de serviços logísticos e a utilização de novas tecnologias são práticas que vêm fazendo parte do contexto empresarial, seja na busca por redução de custos ou por maior flexibilidade, competitividade ou agilidade na execução dos serviços logísticos. Portanto, o processo de terceirização logística pode ser considerado uma alternativa estratégica às empresas que desejam maior flexibilidade operacional, ao mesmo tempo em que buscam reduzir custos e oferecer serviços e produtos customizados, representando ações que as empresas devem executar em busca da diferenciação e, às vezes, inclusive sobrevivência num mercado cada vez mais competitivo e exigente (CAIXETA-FILHO; MARTINS, 2001).

A terceirização geral das operações logísticas constitui prática comum na cadeia logística. Atualmente existem empresas especializadas no mercado para desenvolver tais funções, sendo que a logística de distribuição é um de seus focos, tanto para a empresa contratada quanto para a contratante. Neste sentido, as organizações optam em realizar suas vendas por meio de terceiros para conseguir 
focar em suas atividades principais, além de transferir responsabilidades para a empresa contratada, que passa a fazer parte da cadeia de suprimentos.

Kotler e Keller (2007) retratam que os profissionais de Marketing precisam estar atentos ao transporte, pois a opção do modal de transporte afeta diretamente no custo do final do produto, prazo de entrega e acondicionamento dos produtos, sendo esses fatores que trazem implicações para a satisfação do cliente. Os autores sugerem a este tipo de fornecedores de serviços (transportador-distribuidores) desenvolverem programas de logística com diferentes níveis de serviços e preços, pois acreditam que dessa forma criarão uma estrutura diferenciada por meio de pacotes e serviços específicos.

Ainda nesse aspecto, Ballou (2006) retrata que o transporte deve ser um fator observável, uma vez que os gastos com transportes representam cerca de um a dois terços dos custos ao longo de uma cadeia logística, o que pode impactar no preço final do produto e na competitividade da organização.

Diante do contexto explorado, o presente trabalho tem como tema a adesão à terceirização das operações logísticas. Este contexto é pesquisado em um provedor de inteligência e operações logísticas, que opera no mercado nacional. A organização, chamada AGV Logística², operando desde 1998, iniciou suas atividades na cadeia de frios. Entre os serviços oferecidos pela organização aos seus clientes estão: o frete de mercadorias, rastreamento e monitoramento das entregas, logística reversa, armazéns para estoque, gerenciamento da informação na cadeia de supply chain e consultorias.

O problema de pesquisa foi delineado tendo em vista buscar responder o seguinte questionamento: Quais razões influenciam a terceirização dos serviços de distribuição logística na perspectiva de um provedor logístico que opera no mercado brasileiro?

Como objetivo geral buscou-se entender os motivos que conduzem as empresas a optarem pela terceirização dos serviços de distribuição logística, segundo a visão de um coordenador de operações logísticas.

A escolha do tema para estudo pode, se justificar pela importância do setor de serviços para a economia mundial e brasileira, além de ser uma oportunidade de explorar novos estudos que demonstram a realidade dos serviços logísticos na atualidade e suas tendências futuras, além dos meios e tecnologias que permitem prestar serviços logísticos eficientes, confiáveis e em tempo real. Portanto, mostra-se importante desenvolver estudos voltados para a terceirização de serviços logísticos, assim como a distribuição de produtos, que indiquem os resultados, sejam positivos ou não, bem como os benefícios e/ou desvantagens que este serviço pode oferecer.

\footnotetext{
2 Informações da empresa podem ser visualizadas no site da organização: $<$ http://www.agv.com.br/site/default.asp?TroncoID $=546051 \&$ SecaoID $=804361 \&$ SubsecaoID $=0$ > $>$.
} 


\section{FUNDAMENTAÇÃO TEÓRICA}

Nessa seção são discutidos os argumentos teóricos que sustentam os resultados da pesquisa. Foram tratados nas seções, de forma consecutiva, os temas: logística empresarial e competência estratégica da logística; distribuição; terceirização e serviços de terceirização logística.

\subsection{Logística empresarial e competência estratégica da logística}

A logística empresarial é um esforço realizado de maneira a integrar várias áreas da organização, suprimentos, compras, marketing, finanças, entre outras, com o propósito de criar valor para o cliente com um menor custo possível. Essa tem a função proporcionar satisfação ao cliente, buscando atender suas necessidades, por meio de operações que facilitem os setores de produção e Marketing nas organizações (BOWERSOX, 2007).

Neste mesmo contexto, Ballou (2006) ressalta que a logística pode ser definida como:

um campo relativamente novo da gestão integrada, das áreas tradicionais das finanças, marketing e produção. As atividades logísticas foram durante muitos anos exercida pelos indivíduos. As empresas tiveram permanentemente envolvidas em atividades de armazenagem movimentação (transporte-estoque). A novidade então deriva do conceito da gestão coordenada de atividades inter-relacionadas, em substituição à prática histórica de administra-las separadamente, e do conceito de que logística agrega valor a produtos e serviços essenciais para a satisfação do consumidor e aumento de vendas (BALLOU, 2006, p. 26).

Razzolini Filho (2006; 2011) entende que a logística começa desde o ponto de aquisição da matéria-prima e perpassa toda a organização até o ponto de consumo final. Trata-se de uma visão integradora dos processos de gestão envolvendo todos os elos de uma cadeia produtiva.

Para Dias (1993), a logística é composta de dois subsistemas de atividades, sendo eles a administração de materiais e a distribuição física, cada uma destas áreas envolvendo o controle da movimentação e a coordenação demanda-suprimento.

A logística tende a se aprimorar ao longo dos anos, passando a exercer um papel importante dentro das organizações, por conseguir auxiliar diversos setores, por agregar valor às atividades das empresas e por atender as necessidades dos clientes.

Neste contexto de mudanças das atividades logísticas, Christopher (1998), ressalta a importância de se medir o desempenho em relação aos concorrentes, uma 
vez que a partir dessa mensuração, e das efetivas ações implementadas, a organização pode obter vantagem competitiva. Ainda, a atividade pode permitir e facilitar que seja priorizada a liderança na prestação dos serviços, com reflexos no ganho de vantagens competitivas.

A instalação do primeiro operador logístico no Brasil, a Brasildock's-Pirelli, ocorreu na década de 1980 (LAMBERT; STOCK; ELLRAM, 1998), contudo, foi a partir da primeira década do século XXI que se percebeu um horizonte mais promissor para o mercado de operadores logísticos. Houve um importante salto em qualidade e sofisticação dos processos e do nível de serviços, especialmente a partir da utilização de novas tecnologias. Porém, ainda há o que se aprimorar. Os bons resultados dessa evolução dependem do planejamento contínuo e da integração efetiva com os clientes, para que os operadores possam não apenas oferecer soluções, mas alçarem a categoria de provedores de conhecimento em termos de conhecimentos específicos da atividade que se executa, especialização, soluções inovadoras (RODRIGUES, 2003).

Para Fleury e Figueiredo (2003, p.114), "o mercado de prestação de serviços logísticos vem crescendo muito rapidamente em todo mundo". Para os autores (2003, p.121), "no Brasil, apesar de o processo de terceirização das atividades logísticas ainda ser relativamente recente e de não existirem estatísticas disponíveis, o mercado parece ser elevado".

No Brasil, anualmente, são gastos cerca de R $\$ 192$ bilhões, ou 11,7\% do PIB nacional, com logística. Deste montante, aproximadamente 63\% são direcionados para pagamento de terceiros, ou seja, para os prestadores de serviços logísticos. Esse patamar é similar ao índice de terceirização europeu (65\%) e asiático (62\%), e superior ao norte-americano (47\%), conforme demonstrado na figura 1.

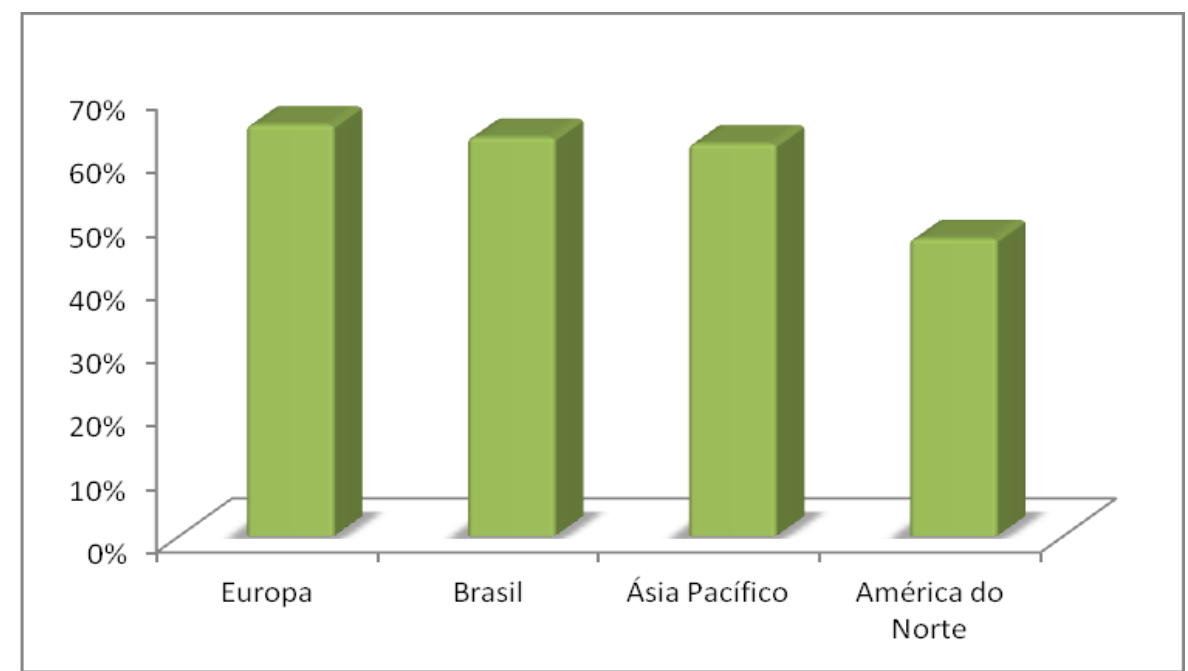

Figura 1: Percentual dos Custos Logísticos para Pagamento de Terceiros Fonte: ILOS - Instituto de Logística e Supply Chain (2009)

REUNIR - Revista de Administração, Contabilidade e Sustentabilidade ISSN: 2237-3667 - Vol.3, no 3, Edição Especial, p. 121-139, 2013. 
Segundo Bowersox (2001), a logística desempenha um papel fundamental, pois, proporciona o sucesso das organizações fornecendo aos clientes entregas de produtos em tempo hábil e dentro dos prazos acordados, ou seja, a logística é vista por muitas empresas como principal recurso estratégico. Nesse aspecto, o autor considera que essa seja um processo que contribui para satisfazer as necessidades dos clientes e organizações, considerando tempo e lugar, possuindo, ainda, profunda relação com o marketing, pois, a meta do desempenho logístico é o serviço ao cliente.

A competência logística pode ser considerada um meio para atrair clientes, sendo o desempenho das atividades logísticas integrante das estratégias de Marketing: preço, promoção, praça e produto, pois nenhuma transferência de posse pode acontecer sem que se cumpram as exigências de tempo e lugar (BOWERSOX, 2001).

Complementando a ideia do autor, Ballou (2007), afirma que

(...) qualquer produto ou serviço perde quase todo seu valor quando não está ao alcance dos clientes no momento e lugar adequados ao seu consumo. A logística controla os valores de tempo e lugar nos produtos, principalmente por meio do transporte, dos fluxos de informações e dos estoques (BALLOU, 2007, p. 37).

Nota-se, então, que a logística é uma forte parceira das atividades do Marketing, agregando valor durante os processos e permitindo o produto no lugar certo na hora desejada.

\subsection{Distribuição}

O Marketing contempla um mix denominado $4 \mathrm{P}^{\prime} \mathrm{s}$, dos quais se entende: preço, praça, produto e promoção. No escopo deste trabalho, ao "P" da distribuição se dará maior ênfase, uma vez que a praça representa os canais de distribuição, que na visão de Kotler e Keller:

\footnotetext{
“(...) começam na fabrica. Os gerentes escolhem um conjunto de depósitos (pontos de estocagem)e os transportadores que entregarão as mercadorias ao destino final no prazo desejado e ao menor custo total .A distribuição física expandiu-se para o conceito mais amplo de gerenciamento da cadeia de suprimentos (SCM- Supply Chain Management)" (KOTLER; KELLER, 2001, p. 519).
}

Para Caixeta-Filho e Martins (2001) a distribuição é a última etapa dentro da cadeia logística antes que o cliente faça sua utilização, portanto, é o conjunto de atividades entre o produto pronto para a saída e sua chegada até o consumidor final, iniciando na fábrica e finalizando no consumidor final. Devido a grande 
movimentação, a distribuição física representa um custo significativo para a maioria dos negócios, e impacta na competitividade, na capacidade de rastreamento; ao entregar os produtos aos consumidores no tempo certo e na hora certa com qualidade.

Na ideia de Dias (1993), do contexto organizacional, a distribuição é o produto certo, em lugar certo, quantidade correta, no tempo certo e no menor custo. Para o autor, para essa definição se torne real, ou que o objetivo da organização seja atingido, é preciso um planejamento dentro do âmbito da distribuição no que se refere ao futuro da empresa, com a intenção de quantificar natureza e extensão da demanda dos produtos em um determinado período futuro para então desenvolver um sistema que satisfaça as demandas previstas.

De acordo com a natureza do negócio, das características do produto e do mercado atuante, a distribuição toma forma diferente e deve ser estabelecida com a intenção de criar uma perfeita distribuição, com menor custo operacional e dentro das normas do plano estabelecido pelas organizações. Podendo a empresa optar por um dos quatro modelos de distribuição (DIAS, 1993):

- Pelo modelo de vendas próprio;

- Pelo sistema de vendas de terceiros;

- Por meio de agentes e representantes comissionários;

- Por meio de distribuidores especializados.

Nesse sentido, Churchill Júnior (2003) ressalta que os fabricantes e varejistas devem decidir se oferecem os produtos pelo varejo com loja ou pelo varejo sem loja, além de escolher os pontos adequados para as lojas e para as operações de varejo sem loja.

\subsection{Terceirização e serviços de terceirização logística}

A terceirização pode ser entendida pelo processo de transferência de atividades de uma empresa a outra, o que, para Giosa (2003), representa:

\footnotetext{
"uma tendência de transferir, para terceiros, atividades que não fazem parte do negócio principal da empresa; ou uma tendência moderna que consiste na concentração de esforços nas atividades essenciais, delegando a terceiros as complementares; ou ainda, um processo de gestão pelo qual se repassam algumas atividades para terceiros, com os quais se estabelece uma relação de parceria, ficando a empresa concentrada apenas em tarefas essencialmente ligadas ao negócio em que atua" (GIOSA, 2003, p. 83).
} 
A prática da terceirização não é novidade no mundo dos negócios. As empresas, tanto nos países desenvolvidos como nos países em desenvolvimento, como o Brasil, praticam a contratação, via prestação de serviços, de empresas especializadas em atividades especificas que não cabem ser desenvolvidas no ambiente interno da organização ou que não constituam foco do negócio das empresas. Sabe-se que em vários segmentos como produção, transporte, vigilância é utilizada com freqüência a contratação de serviços de terceirização logística (NAZÁRIO; ABRAHÃO, 2002).

$\mathrm{O}$ autor afirma que a terceirização pode ser visualizada como uma técnica moderna de administração que se baseia num processo de gestão, que leva a mudanças estruturais da empresa a mudanças de cultura, de procedimentos, de sistemas e controles, com o objetivo de atingir melhores resultados, permitindo a concentração dos esforços e energia dos gestores para a atividade principal da organização (NAZÁRIO; ABRAHÃO, 2002).

Para Rios e Gondin (2010), a terceirização é, provavelmente, uma das práticas de gestão mais difundidas. Tal fato, segundo os autores, se justifica, entre outros aspectos, por permitir uma alternativa eficaz para reduzir custos com manutenção de pessoal.

\footnotetext{
“A prática atual, conforme é hoje definida, tem suas origens na II Guerra Mundial, mais especificamente pela forte demanda do mercado de flexibilidade e qualidade. Influenciada pelas ferramentas do modelo japonês, com foco na qualidade e celeridade dos processos de produção, a terceirização passou a ser vista como prática de gestão diretamente atrelada ao incremento à competitividade e de garantia de qualidade" (RIOS; GONDIN, 2010, p. 5).
}

Neste sentido, a terceirização busca a melhora da vantagem competitiva da organização, por meio do direcionamento de suas atividades as suas competências essenciais (PRAHALAD; HAMEL, 1990). Este argumento é corroborado por Fawcett e Fawcett (1995), ao afirmarem que a possibilidade de a empresa direcionar seus esforços em suas competências principais pode torna-la mais competitiva, motivo pelo qual a prática tem sido adotada por diversas organizações.

A terceirização pode representar um processo de desintegração vertical, a partir do direcionamento dos esforços organizacionais a atividade fim, cabendo a terceiros a realização de atividades meio, de forma mais especializada (LEITE, 2004).

Para Sato et al. (2013),

\footnotetext{
"essa exploração de recursos externos, [...] pode favorecer a incorporação rápida de mudanças à organização. Mas, se por um lado ela facilita a adaptação organizacional às novas exigências ambientais, por outro lado,
} 
exige que as organizações desenvolvam habilidades para administrar os relacionamentos organizacionais" (SATO et al., 2013, p. 3)

Portanto, ressalta-se o caráter essencial da gestão nos processos de terceirização, tanto no que se refere aos custos e processos envolvidos, quanto ao treinamento de pessoal (RIOS; GONDIN, 2010; SARAIVA; MERCÊS, 2013).

Segundo Rezende (2001), a terceirização das atividades logísticas cresceu muito, podendo variar desde uma simples locação de empilhadeira até complexas operações em regime de fulfillment (toda operação logística terceirizada).

Nos últimos anos o mercado nacional está aquecido, aumentando consideravelmente a receita média por prestador de serviço logístico (PSL), que saiu de $R$ \$ 32 milhões, em 2000, para $R \$ 203$ milhões em 2007, o que representou um crescimento anual de quase $30 \%$. Entre as explicações para o indicador é possível elencar algumas fusões e aquisições e o crescimento da economia, que fez o volume dos serviços terceirizados aumentarem naturalmente. Além do mais, com o passar do tempo, diversos foram os PSLs que souberam interpretar as necessidades de seus clientes, aumentando seu portfólio e, consequentemente, suas receitas (BARROS, 2009). A figura 2 apresenta a evolução da receita média/PSL.

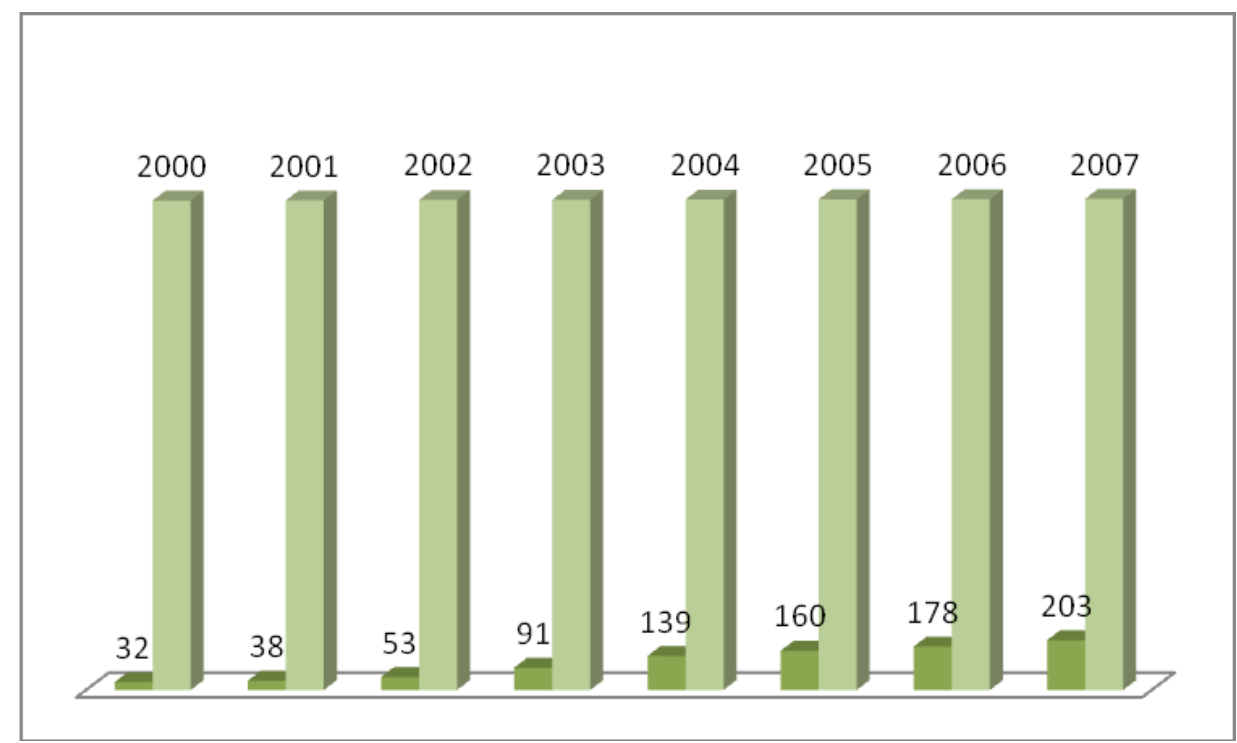

Figura 2: Evolução da Receita Média / PSL

Fonte: ILOS - Instituto de Logística e Supply Chain (2009)

Atualmente, a maioria das atividades logísticas pode ser terceirizada, pois existem empresas especializadas, desde locação de mão-de-obra, até as LLP - Leading Logistics Provider (Principal Fornecedor de Serviços Logísticos), também os PSL, prestadores, operadores de serviços logísticos. 
Vivaldini e Souza (2006) ressaltam que alguns prestadores atuam com uma gama de atividades que atendem diversos processos operacionais, assim como armazenagem, transporte, distribuição montagens de kits, entre outros serviços, conforme a necessidade de seus clientes.

Para Rezende (2001), entre os serviços disponíveis de terceirização logística, podem ser destacados: transporte rodoviário, roteirização, rastreamento; locação de mão-de-obra, equipamentos, armazéns infláveis e estruturais, embalagens retornáveis; armazéns gerais (sem ou com filial) e alfandegados; comércio exterior agenciamento de transportes, operações de carga e descarga (portuária, ferroviária e rodoviária), desembaraço aduaneiro; unitização de cargas, estufamento e desova de contêineres; compras; tecnologia de Informação (ERP, WMS, código de barras); Coleta programada (milk run), cross docking (transbordo sem estocagem), recebimento, inspeção, estocagem, abastecimento de linha (line feeding), sequenciamento; processamento e separação de pedidos (picking), embalagem, acumulação, expedição.

Todos estes serviços citados por Rezende (2001) podem ser disponibilizados por um operador logístico, que tem a responsabilidades do início ao fim da cadeia de suprimentos, ou seja, desde a coleta de materiais, transporte, entrega e/ou recebimento, armazenagem, endereçamento, separação, realização de inventários, controle de estoques, expedição e nova distribuição. Os principais serviços de terceirização logística podem ser observados na figura 3.

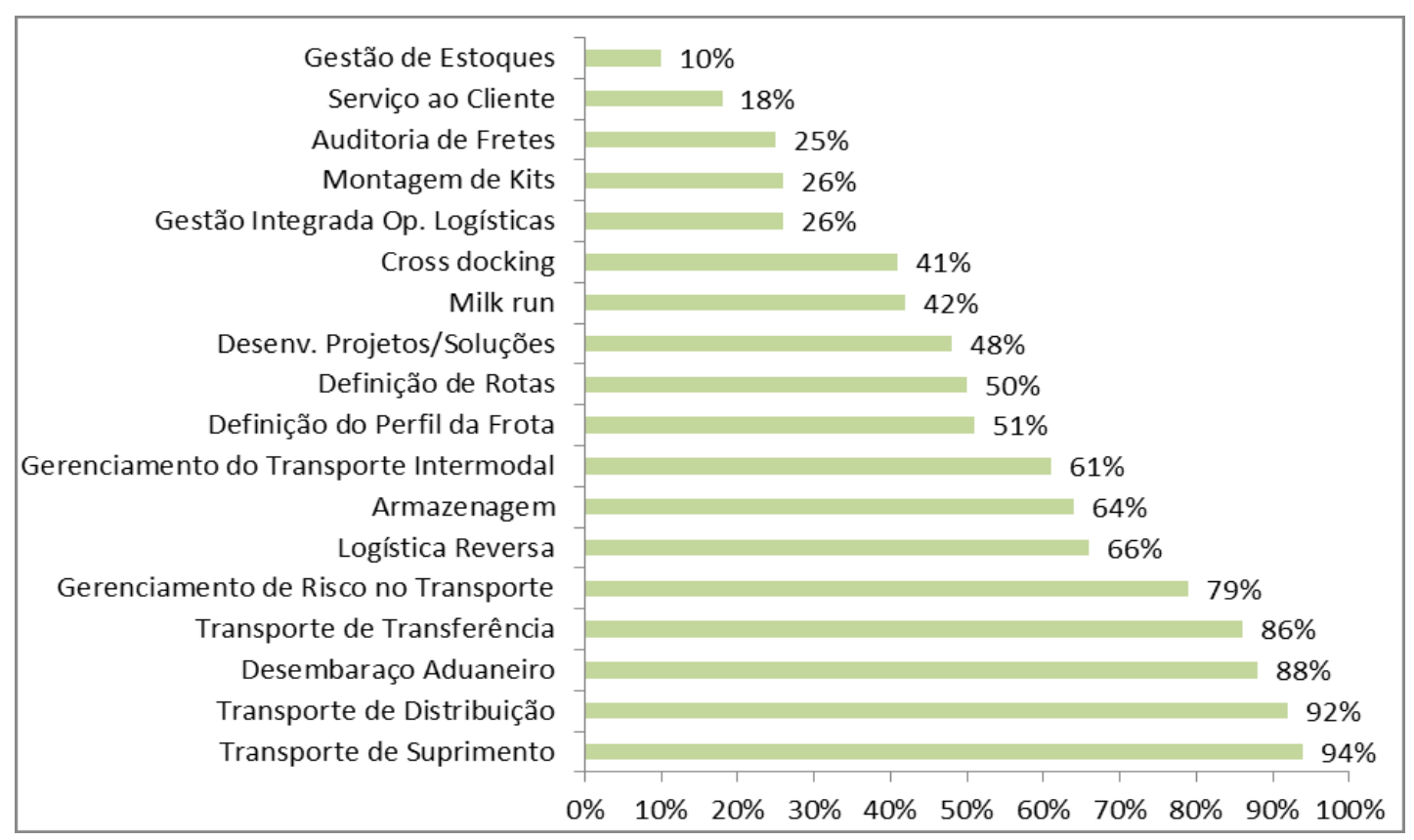

Figura 3: Principais Atividades Logísticas Terceirizadas

Fonte: ILOS - Instituto de Logística e Supply Chain (2009) 
A partir das ideias apresentadas, entende-se que os serviços de terceirização logística estão cada vez mais modernos, por meio da utilização de técnicas, equipamentos e de tecnologias voltadas para melhorar as operações nas organizações, possibilitando assim bom desempenho do operador logístico.

Para Fleury e Figueiredo (2003), os possíveis motivos para terceirizar as atividades logísticas podem estar relacionados a

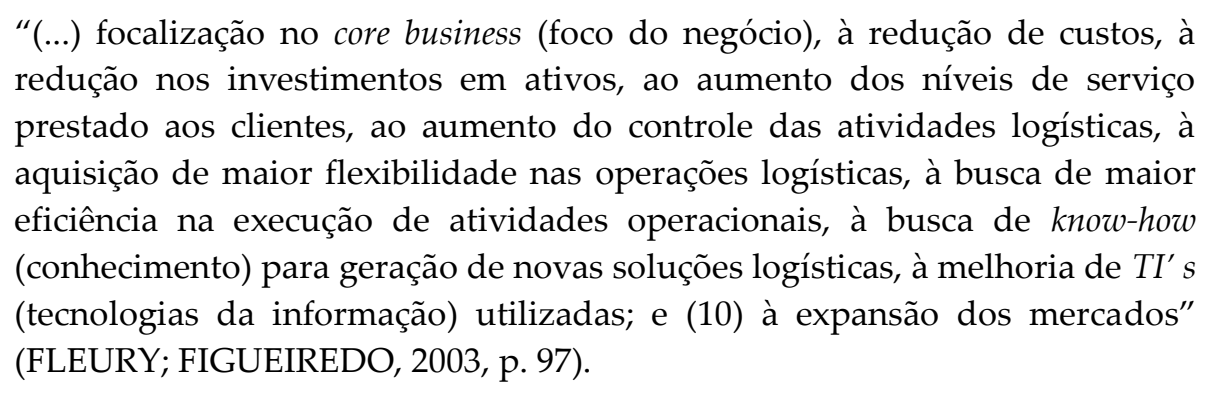

Para Rezende (2001), os motivos para terceirizar as atividades logísticas são vários, entre os quais se destacam: maior dedicação ao próprio negócio (core business); reduzir e melhorar o controle dos custos logísticos; reduzir problemas trabalhistas; absolver know-how (experiências); evitar investimentos e substituir custos fixos por variáveis; utilizar novos canais de distribuição; aperfeiçoar a logística como forma de diferencial competitivo.

A figura 4 aponta os principais motivos que levam a terceirização das atividades logísticas.

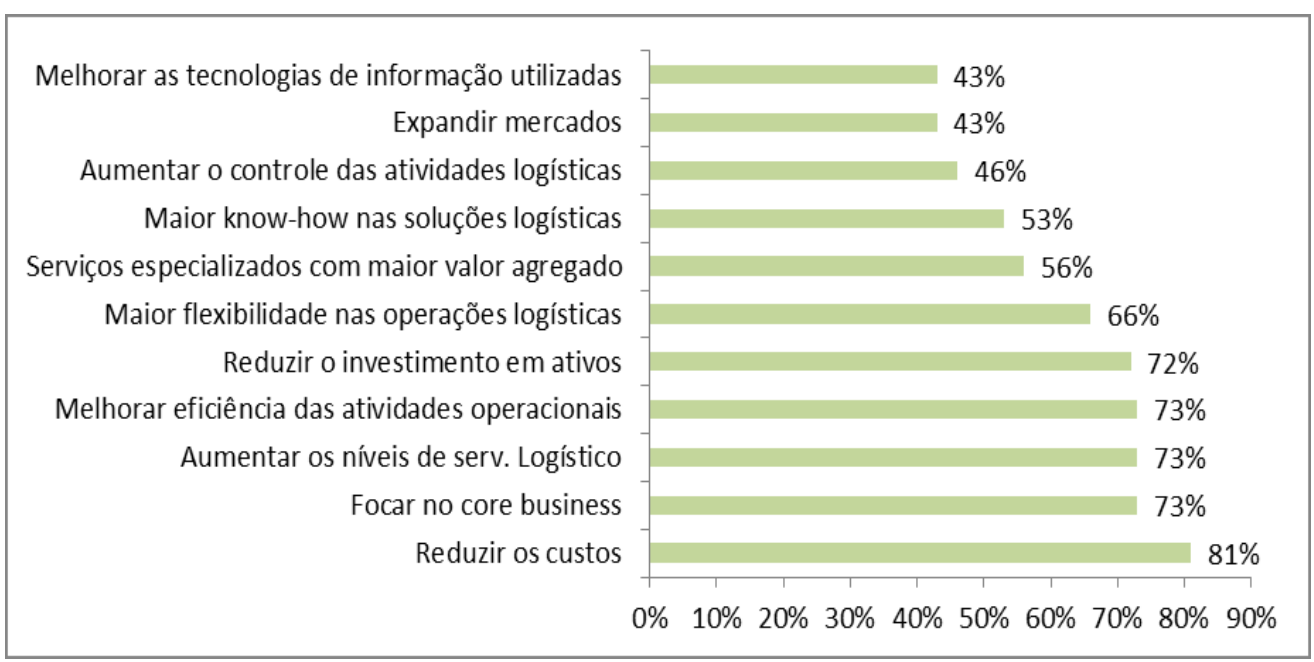

Figura 4: Motivos para a Terceirização

Fonte: ILOS - Instituto de Logística e Supply Chain (2009) 
Ressalta-se, conforme discutido por Bandeira, Maçada e Mello (2010), que, apesar de a redução nos custos representar um dos principais motivos para a terceirização dos serviços logísticos, o processo pode conduzir a falhas corporativas e a elevação do custo logístico, diante de deficiências no processo decisório.

Esta deficiência estaria relacionada, principalmente, a racionalidade limitada e existência de oportunismo, por parte dos agentes envolvidos (BANDEIRA; MAÇADA; MELLO, 2010).

Na seção que segue discutem-se os aspectos metodológicos para a condução da investigação proposta, a partir da apresentação teórica relacionada às perspectivas ora abordadas na entrevista.

\section{MÉTODO DE PESQUISA}

Nesta seção é apresentada a unidade observatória e a classificação do estudo, seguindo os critérios: quanto aos fins, quanto aos meios, quanto ao tipo de coleta.

\subsection{Unidade observatória}

A unidade observatória deste estudo foi a empresa AGV Logística, fundada em 1998 na cidade de Vinhedo - SP. A empresa atualmente é um importante provedor de inteligência e operações logísticas no país possuindo parcerias com clientes de grande porte no mercado brasileiro. Atua nos seguintes segmentos: automotivo, de bens de consumo, industrial e serviços, químico, saúde animal, saúde humana, serviços bancários, tecnologia e varejo.

A empresa presta diversos serviços relacionados às operações logísticas, entre os quais: armazenagem e gestão de estoque; transporte e distribuição; transporte dedicado; transporte de produtos sensíveis; logística promocional; logística reversa; logística de carga extra-pesada; fornecimento de embalagens e insumos; gestão de operações in house; consultoria e projetos logísticos; soluções especializadas em sistemas - TI, assessoria em comércio exterior; importação e exportação.

Dentre os serviços prestados pela empresa, o foco pesquisa se concentra na etapa de terceirização dos serviços de distribuição logística realizada pela filial Contagem III localizada na cidade de Contagem - MG, responsável por realizar a operação logística da empresa Betha, (aqui assim denominada para garantir a confidencialidade da informação). A empresa Betha é, uma das maiores empresas de bens de consumo do mundo, fabricante de produtos de higiene pessoal e limpeza, alimentos e sorvetes, presente em mais de 100 países. 


\subsection{Tipo de pesquisa}

Quanto aos fins a pesquisa se caracteriza como descritiva, que segundo Vergara (2007) expõe as características de certa população ou um determinado fenômeno. Para Santos (2000) a pesquisa descritiva é um tipo de levantamento de características conhecidas que pertencem ao fato, ao problema ou ao fenômeno de estudo. Neste tipo de pesquisa os dados devem ser observados, registrados, analisados, classificados e interpretados sem que haja interferência do pesquisador sobre eles.

Foi realizada uma pesquisa qualitativa básica, que tem como finalidade compreender o significado de determinado fenômeno para os sujeitos nele envolvido (MERRIAN, 2002), no caso deste trabalho a terceirização de serviços logísticos.

\subsection{Tipo de coleta e análise dos dados}

Os dados foram coletados a partir de entrevista, com a utilização de um roteiro semiestruturado. Para Godoi e Mattos (2010, p. 304), a entrevista baseada em roteiro semiestruturado constitui uma das modalidades principais de entrevista qualitativa, sendo essa "caracterizada pela preparação desse roteiro e por dar ao entrevistador flexibilidade para ordenar e formular as perguntas durante a entrevista". Para tanto foi entrevistado, em maio de 2013, o coordenador de operações logísticas, que trabalha na AGV Logística há seis anos.

A análise dos dados se deu por meio da análise de conteúdo, que segundo Bardin (1997), se refere a um conjunto de instrumentos metodológicos que garante objetividade, sistematização e influência aos diversos discursos. Trata-se de um método para analisar pesquisas qualitativas, no intuito de se ter maior compreensão do discurso.

\section{APRESENTAÇÃO E DISCUSSÃO DE RESULTADOS}

A pesquisa buscou verificar quais razões influenciam a terceirização dos serviços de distribuição logística em um provedor logístico que opera no mercado brasileiro.

Na visão do entrevistado, a empresa AGV Logística presta um serviço de qualidade, atendendo as necessidades do cliente. Para atingir esta qualidade a empresa se destaca pelo conhecimento adquirido no mercado há quase 16 anos, além da estrutura, tecnologia e desenvolvimento do capital humano. Segundo o entrevistado, o cliente percebe esta qualidade por meio da evolução dos resultados entregues, além da flexibilidade operacional do operador logístico. Para tanto afirma: 
"a AGV presta sim um serviço de qualidade, levando em consideração a estrutura e tecnologia encontrada em nossos CD's [Centro de Distribuição] pelo Brasil (...)" (Entrevistado).

Quanto aos motivos que levam a empresa Betha a terceirizar seus serviços logísticos nota-se que, na visão do coordenador de operações logísticas, o fator determinante foi a relação de confiança já existente entre empresa Betha e AGV Logística, além da redução de custos e flexibilidade no processo. Este entendimento corrobora com a afirmação de Fleury e Figueiredo (2003), quando afirmam para se terceirizar os serviços logísticos é levado em consideração a

\footnotetext{
“(...) focalização no core business (foco do negócio), à redução de custos, à redução nos investimentos em ativos, ao aumento dos níveis de serviço prestado aos clientes, ao aumento do controle das atividades logísticas, à aquisição de maior flexibilidade nas operações logísticas, à busca de maior eficiência na execução de atividades operacionais, à busca de know-how (conhecimento) para geração de novas soluções logísticas, à melhoria de $T I^{\prime} s$ (tecnologias da informação) utilizadas; e (10) à expansão dos mercados" (FLEURY; FIGUEIREDO, 2003, p. 97).
}

Quanto à melhoria das tecnologias de informação, o entrevistado apontou que a empresa Betha considera a tecnologia de informação um fator importante, pois, a inteligência sistêmica deixa o profissional livre para se preocupar com a melhoria no processo. Ressalta-se que com o crescimento da AGV e a necessidade cada vez maior de customização, a empresa de tecnologia que atendia as operações da AGV foi incorporada e passou a fazer parte da organização. "Mesmo estando comprovado que o maior bem de uma organização seja o capital humano, é impossível prestar um serviço diferenciado sem tecnologia de ponta" (Entrevistado).

Segundo o Entrevistado, a empresa Betha opta em terceirizar seus serviços logísticos pensando em reduzir os custos de contratação, desenvolvimento e manutenção de mão de obra qualificada, investimento em tecnologia de informação, em equipamentos de movimentação e custos de manutenção predial. Partindo do princípio que o operador consegue melhores custos por se tratar de sua atividade fim.

Apesar de o fator custo ser importante, na visão do entrevistado, o principal fator que leva a empresa Betha a terceirizar sua operação logística é poder dedicar-se a seu negócio, o que corrobora com Rezende (2001) quando afirma que os motivos para terceirizar as atividades logísticas são vários, entre os quais de destacam: maior dedicação ao próprio negócio (core business).

Quanto à qualidade dos serviços prestados pela AGV Logística à Betha, são utilizados indicadores de desempenho entre os quais: índice de qualidade na entrega (IQE) - Apresenta o percentual de entregas com problemas (faltas, sobras, avarias); aderência ao INBOUND (Dentro da operação) - Mede a tonelagem recebida em 
relação ao contratado; aderência ao OUTBOUND (Externo á operação) - Mede a tonelagem expedida em relação ao contratado; tempo de permanência - Mede o tempo que os veículos aguardam no site para carga e descarga. "Na verdade estes indicadores são do cliente, sendo que algumas informações são alimentadas por nós. Temos também vários indicadores paralelos, que utilizados para enxergar produtividade e possíveis gap's operacionais." (Entrevistado). Quanto a AGV Logística existem também índices internos para demonstrar a produtividade dos serviços executados.

Atualmente, a maioria das atividades logísticas pode ser terceirizada, pois existem empresas especializadas, desde locação de mão-de-obra, até as LLP - Leading Logistics Provider (Principal Fornecedor de Serviços Logísticos), também os PSL, prestadores, operadores de serviços logísticos. Deste modo, a AGV Logística trabalha de forma flexível, sempre idealizando "entregar a seu cliente algo a mais do o que contratado" (Entrevistado).

Na visão do entrevistado, de um modo geral, são vários os fatores que devem ser levados em consideração ao se optar pela terceirização dos serviços logísticos, mas o mais importante é a tranquilidade que a empresa Betha adquire para focar na sua atividade principal, além de ser uma considerável redução de custos levando em consideração que sua logística está entregue a uma empresa especializada e preparada para lidar com problemas no dia a dia que demandam tempo e expertise em suas soluções.

\section{CONSIDERAÇÕES FINAIS}

Buscou-se inicialmente verificar as razões que influenciam a terceirização dos serviços de distribuição logística na perspectiva de um provedor logístico que opera no mercado brasileiro. Verificou-se que na atualidade o mercado tem apresentado novas demandas de serviços e produtos altamente especializados. Com isso vem aumentando o número de organizações prestadoras de serviços que se colocam no mercado por meio da terceirização.

No Brasil, este crescimento é de em média 30\% anualmente. Os gastos com logística representam aproximadamente $11,7 \%$ do PIB nacional, sendo que $63 \%$ desse percentual correspondem à terceirização dos serviços logísticos. Isto equipara o número de terceirizações logísticas do Brasil aos países europeus e asiáticos. Rezende (2001, p. 35) entende que a terceirização das atividades logísticas cresceu muito, desde uma simples locação de empilhadeira até complexas operações em regime de fulfillment (toda operação logística terceirizada).

$\mathrm{Na}$ organização pesquisada, os principais motivos identificados como importantes para a contratação dos serviços de terceirização das atividades logísticas são o custo e a intenção de focar os esforços no próprio negócio, sendo estes, 
também, os fatores os mais ressaltados na literatura consultada. $O$ estudo de caso na AGV Logística permite inferir, ainda, que a empresa Betha leva em consideração a confiança que existe entre a parceria firmada.

Sobre o custo, cabe ressaltar que apesar de se mostrar como fator inicial da intenção de se terceirizar, este deve estar associado a possibilidade de maior dedicação a atividade fim, ou core business.

Sobre a customização presente na execução das atividades logísticas verificouse que a prestação de um serviço adequado às necessidades do cliente é um diferencial competitivo. A logística tem a função de proporcionar satisfação ao cliente, buscando atender suas necessidades, por meio de operações que facilitem os setores de produção e Marketing nas organizações (BOWERSOX, 2007).

No estudo de caso, percebe-se que esta customização está presente com os serviços de tecnologia de informação prestados. A AGV Logística incorporou a empresa de tecnologia de informação ao seu grupo, a fim de proporcionar maior flexibilidade a seus clientes, inclusive para a empresa Betha, que possui toda sua operação desenhada conforme suas necessidades.

A empresa Betha direciona a AGV Logística os indicadores que avaliam toda a operação, sendo esses confrontados com indicadores internos para medir o desempenho operacional da AGV Logística.

Foi possível perceber que para a organização Betha o desenvolvimento tecnológico, especialmente aquele pautado no desenvolvimento das tecnologias de informação e comunicação, permitiu maior flexibilização no processo de terceirização, especialmente pelos controles que se tornaram possíveis, além do aproveitamento do know-how do provedor (AGV Logística).

Tendo em vista que o estudo constitui uma pesquisa qualitativa básica ressalta-se que não há intenção de generalização dos resultados, e sim de entendimento do fenômeno. Portanto, como limitação do estudo pode-se citar o método escolhido para coleta dos dados. Como sugestão para estudos futuros, acredita-se que uma triangulação, a partir da comparação entre argumentos do operador logístico e do cliente (contratante) poderia ampliar o entendimento do fenômeno. Ainda, sugere-se a realização de pesquisas que envolvam outros operadores logísticos, ampliando o escopo de coleta de dados para métodos generalizáveis.

\section{REFERÊNCIAS}

AGV LOGÍSTICA. Apresentação da empresa. Disponível em: $<$ http://www.agv.com.br/site/default.asp?TroncoID $=546051 \&$ SecaoID $=804361 \&$ Subse caolD $=0>$. Acesso em 25 de out. 2012. 
BALLOU, Ronald H. Gerenciamento da Cadeia de Suprimentos: Logística empresarial. 5 ed. Porto Alegre: Bookman, 2006.616P.

BANDEIRA, Renata A. M.; MAÇADA, Antônio C. G.; MELLO, Luiz C. B. Terceirização Logística: Fatores de decisão sob a perspectiva do contratante. In: XXXIV Encontro da ANPAD. Anais do EnANPAD. Rio de Janeiro/RJ, 2010.

BARDINI, Laurence. Análise de conteúdo. Lisboa: Edições 70, 1997.

BOWERSOX, Donald J.; CLOSS, David J. Logística empresarial: O processo de integração da cadeia de suprimento. São Paulo: Atlas, 2007. 594p.

BOWERSOX, Donald J. ; CLOSS, David J. Logística Empresarial: o processo de integração da cadeia de suprimento. São Paulo: Atlas, 2001. 594p.

CAIXETA-FILHO, José; MARTINS, Ricardo S. (organizadores). Gestão logística do transporte de cargas. São Paulo: Atlas, 2001. 296p.

CHURCHILL JÚNIOR, Gilbert A., PETER, Paul J. Marketing criando valor para os clientes. 2 ed. São Paulo: Saraiva 2003. 626p.

CHRISTOPHER, Martin. Logística e gerenciamento da cadeia de suprimentos: estratégias para a redução de custos e melhoria dos serviços. São Paulo: Pioneira, 1998. 240p.

DIAS, Marco P. Administração de Materiais: Uma Abordagem Logística. 4 ed. São Paulo, Atlas, 1993. 399p.

FAWCETT, Stanley. E.; FAWCETT, Stanley. A. The firm as a value adds system: integration logistics, operations, and purchasing. The International Journal of Physical Distribution and Logístics Management, v. 25, n. 5, p. 24-42, 1995.

FLEURY, Paulo F.; FUIGUEIREDO, Kleber F.; WANKE, Peter. Logística e Gerenciamento da Cadeia de Suprimentos. Rio de Janeiro: Atlas, 2003. 483p.

GIOSA, Lívio. Terceirização: uma abordagem estratégica. 5 ed. São Paulo: Pioneira, 2003. 144p. 
GODOI, Christiane. K.; MATTOS, Pedro L. C. L. Entrevista qualitativa: instrumento de pesquisa e evento dialógico. In: GODOI, Christiane K.; BANDEIRA-DE-MELLO, Rodrigo; SILVA, Anielson B. (org.). Pesquisa Qualitativa em estudos organizacionais: paradigmas, estratégias e métodos. 2. ed. São Paulo: Saraiva, 2010. Cap. 10, pp. 301-323.

ILOS - Instituto de Logística e Supply Chain. 2009. Disponível em: <http://www.ilos.com.br/web/index.php?option=com_content\&task=view\&id=738\&It emid=74>. Acesso em 23 abr. 2013.

KOTLER, Philip. Marketing para o século XXI: como criar, conquistar e dominar mercados. São Paulo: Editora Futura, 2001. 305p.

LAMBERT, Douglas M.; STOCK, James R.; ELLRAM, Lisa M. Fundamentals of logistics management. New York: Irwin-McGraw Hill, 1998.

LEITE, Jaci C. Terceirização em Informática. São Paulo: Makron Books, 2004.

MERRIAM, Sharan B. Qualitative research in practice: examples for discussions and analysis. San Francisco: Jossey-Bass, 2002.

NAZÁRIO, Paulo; ABRAHÃO, Fabio; Terceirização Estruturada: O Uso do RFI Request For Information - Como Ferramenta de Seleção de Operadores Logísticos, Revista Tecnologística. Ed. 79, jun/2002.

PRAHALAD, Coimbatore K.; HAMEL, Gary. The Core Competence of the Corporation. Harward Business Review, 1-15, 1990.

RAZZOLINI FILHO, Edelvino. Logística: Evolução na administração. Curitiba: Juruá, 2006.

RAZZOLINI FILHO, Edelvino. Logística Empresarial no Brasil: tópicos especiais 2 ed. São Paulo: Ibpex, 2011.

RIOS, Mino C.; GONDIN, Sônia M. G. Contratos Psicológicos e Terceirização: um estudo das relações entre vínculos e as práticas de gestão de pessoas. Organização \& Sociedade, v. 17, n. 55, p. 689-703, out./dez. 2010. 
RODRIGUES, Paulo R. A. Introdução aos Sistemas de Transporte no Brasil e à Logística Internacional. 3 ed. São Paulo: Aduaneiras, 2003. 180p.

REZENDE, Carlos A. Terceirização das Operações Logísticas: avaliações e tendências. Revista intra-LOGÍSTICAS, mar./ 2001. Disponível em:

$<$ http://www.imam.com.br/consultoria/component/docman/doc_view/27-parte-1operacoes-proprias-ou-terceirizadas?Itemid=15> Acesso em 13 out. 2012.

SANTOS, Antonio R. Metodologia Científica: a construção do conhecimento. 3 ed. Rio de Janeiro: DP\&A Editor, 2000. 166p.

SARAIVA, Luiz A. S.; MERCÊS, Ronaldo E. Terceirização na Gestão da Manutenção: estudo de caso de uma mineradora. Revista de Administração da UNIMEP, v. 11, n. 1, jan./abr. 2013.

SATO, Kawana H. et al. O processo de terceirização de serviços hoteleiros: motivações e fundamentos teóricos. Revista Brasileira de Pesquisa em Turismo, v. 7, n. 1, p. 129-148, jan./abr. 2014.

VERGARA Sylvia C. Projetos e relatórios de pesquisa em Administração. 8 ed. São Paulo: Atlas, 2007. 96p.

VIVALDINI, Mauro; SOUZA, Fernando. Operador Logístico e Manutenção Terceirizada: Um Estudo Sobre Performance Baseada na Empresa Foco da Cadeia de Suprimentos, Salvador, p. 2, setembro de 2006. 